\title{
Variations in Metastasis Site by Primary Location in Colon Cancer
}

\section{Citation}

Amri, Ramzi, Liliana G. Bordeianou, Patricia Sylla, and David L. Berger. 2015. “Variations in Metastasis Site by Primary Location in Colon Cancer." In Journal of Gastrointestinal Surgery 19 , no. 8: 1522-1527. doi:10.1007/s11605-015-2837-9.

\section{Published Version}

doi:10.1007/s11605-015-2837-9

\section{Permanent link}

http://nrs.harvard.edu/urn-3:HUL.InstRepos:33758667

\section{Terms of Use}

This article was downloaded from Harvard University's DASH repository, and is made available under the terms and conditions applicable to Other Posted Material, as set forth at http:// nrs.harvard.edu/urn-3:HUL.InstRepos:dash.current.terms-of-use\#LAA

\section{Share Your Story}

The Harvard community has made this article openly available.

Please share how this access benefits you. Submit a story.

Accessibility 
In primary tumors of the colon, the presence of locoregional and distant metastasis has important consequences for the prognosis and the preferred treatment approach for the individual patient. ${ }^{1}$ In the absence of clinical and radiological suspicion of distant metastasis, treatment will be surgical with curative intent in virtually all cases. If lymphatic disease is also absent in the surgical resection specimen, adjuvant therapy is rarely required and most patients will only need regular follow-up to monitor recurrence.

Colonic malignancies have a tendency to spread to the pericolic lymphatics, followed by more distant lymph node stations, with distant hematologic spread usually seen as a last stage of dissemination. These steps are however not obligatorily sequential, nor is lymphatic spread a prerequisite of distant metastasis, as hematologic spread can occur in the absence of involved lymph nodes, even in necropsies. ${ }^{2}$ Distant metastatic spread is present in about one in five patients at baseline, ${ }^{3}$ most often to the liver, followed by the lungs and the peritoneum. Less typical sites of metastasis once colonic tumor cells reach the systemic arterial circulation are numerous and include the bones and bone marrow, the brain, and more rarely other parts of the gastrointestinal tract, as well as other solid organs including the kidney, the spleen, and adrenal glands.

Despite being studied in detail, most of the research aimed at identifying patterns of metastasis combine patients affected by cancers of the colon and rectum. ${ }^{4}$ If colonic malignancies are studied separately, it will commonly be done by clustering all regions of the colon together. Considering that lymphovascular drainage passes through distinct and anatomically discrete vessels for right-sided, left sided and sigmoid tumors, it could potentially have a significant impact on the specific rates and patterns of metastatic spread. Our aim in this study is to verify whether metastasis patterns differ for each of the major resection regions in malignancies of the colon. 


\section{Patients and methods}

Data for this research was extracted from a prospectively maintained database that included all colon cancer patients treated surgically for colon cancer at Massachusetts General Hospital in the 2004 through 2011 timeframe. From this dataset, all patients undergoing a primary, single-segment resection (i.e. right colectomy, left colectomy, or sigmoid resection, excluding total and transverse colectomies) were included for further analysis. Records were reviewed for presentation and admission characteristics. Baseline metastasis was considered any metastatic disease that was suspected and confirmed within 30 days of the index procedure. Any metastasis identified past this limit will be considered metastasis in follow-up.

\section{Statistical analysis}

Statistical analysis was performed using SPSS statistical software (IBM Corp. Released 2013. IBM SPSS Statistics for Windows, Version 22.0. Armonk, NY: IBM Corp.). Statistical significance was defined as a two-sided P-value of 0.05. Differences in dichotomous outcomes were assessed using a chi-square $\left(\chi^{2}\right)$ test. Significance of the differences in continuous outcomes over all three resection groups was performed using a Kruskal-Wallis $\mathrm{H}$ test, while any comparison between a single subgroup and the remainder of the population was performed through one-way analysis of variance (ANOVA) analysis. Lastly, differences in metastatic rates were assessed in multivariable analysis adjusted for baseline AJCC staging and accounting for any time-related biases using Cox proportional hazards models, which will compare univariate hazard ratio (HR) and 95\% confidence interval $(95 \% \mathrm{CI})$ of the events occurring with the multivariate $\mathrm{HR}(\mathrm{mHR})$.

\section{Results}

Baseline characteristics

Baseline characteristics were not significantly different between the three major resection groups, except for age and the rate of preexisting polyposis, which did differ significantly between 
groups (both $\mathrm{P}<0.001)$. In terms of group-specific differences, right-sided resections were shown to have significantly fewer male patients (46.9 vs. 54.4\%; $\mathrm{P}=0.022$ ) and higher rates of preexisting polyposis (15.1 vs. 6.9\%; $\mathrm{P}<0.001)$. Sigmoid resections had a significantly higher proportion of male patients (55.1 vs. $47.9 \%$; $\mathrm{P}=0.04$ ), obese patients (34 vs. $26.6 \%$; $=0.024)$, and current smokers (14.4 vs. 9.8\%; $\mathrm{P}=0.04)$, while having significantly lower rates of preexisting polyposis (6.1 vs. $13.9 \%$; $\mathrm{P}<0.001)$.

\section{Table 1. Baseline characteristics of the included cohort}

\begin{tabular}{lllll}
\hline & Right & Left & Sigmoid & P \\
& $N=557$ & $N=127$ & $N=263$ & \\
\hline Age (median, IQR) & $70 \pm 19^{\star \star \star}$ & $65 \pm 17$ & $61 \pm 22^{\star \star \star}$ & $<0.001$ \\
Gender (\% male) & $46.9 \%^{*}$ & $52.8 \%$ & $55.1 \%^{*}$ & 0.068 \\
Minority patients (\%) & $9.0 \%$ & $11.0 \%$ & $11.4 \%$ & 0.5 \\
Obese (\%) & $26.7 \%$ & $26.2 \%$ & $34.0 \%^{\star}$ & 0.086 \\
Current smoking (\%) & $10.2 \%$ & $7.9 \%$ & $14.4 \%^{*}$ & 0.093 \\
Former smoking (\%) & $41.5 \%$ & $34.6 \%$ & $42.2 \%$ & 0.32 \\
Ever alcohol abuse (\%) & $6.6 \%$ & $9.4 \%$ & $6.1 \%$ & 0.46 \\
Earlier colon cancer (\%) & $2.2 \%$ & $2.4 \%$ & $2.3 \%$ & 0.99 \\
Preexisting IBD (\%) & $1.6 \%$ & $2.4 \%$ & $1.5 \%$ & 0.82 \\
Preexisting polyposis (\%) & $15.1 \% \%^{\star \star \star}$ & $8.7 \%$ & $6.1 \% \%^{* \star}$ & $<0.001$ \\
Screening diagnosis (\%) & $25.7 \%$ & $22.8 \%$ & $30.0 \%$ & 0.251 \\
Emergency diagnosis (\%) & $11.0 \%$ & $5.5 \%$ & $8.0 \%$ & 0.11 \\
\hline
\end{tabular}

${ }^{* / * * / * * *}$ : Values significantly different from the remaining resection regions: ${ }^{*}: P<0.05 ;{ }^{* *}: P<0.01^{* * *}: P<0.001$.

\section{Perioperative outcomes}

Right-sided procedures had a significantly shorter median procedure time (108 vs. 139 minutes; $\mathrm{P}<0.001$ ), while sigmoid resections had a median admission that was one day shorter (4 vs. 5 days; $\mathrm{P}=0.022$ ). In terms of postoperative pathology, statistically significant variations existed between groups in rates of high-grade disease $(\mathrm{P}<0.001)$ and perineural disease $(\mathrm{P}=0.044)$ : high grade disease being significantly more prevalent in right-sided tumors $(24.3$ vs. $12.8 \% ; \mathrm{P}<0.001)$ and less so in sigmoid resections $(10.8$ vs. $22.8 \%$; $\mathrm{P}<0.001)$, while the inverse relationship was shown in the rates of perineural disease, which was lowest in right-sided tumors $(21.0$ vs. $27.3 \% ; \mathrm{P}=0.026)$ and highest in sigmoid tumors $(29.0$ vs. $21.6 \%$; $\mathrm{P}=0.016)$. In terms of overall metastasis rates within 
30 days of admission, sigmoid tumors had the highest incidence at $20.2 \%$ (vs. $15.9 \%$ in other tumors; $\mathrm{P}=0.12$ ). This was most likely due to the significantly higher rate of liver metastasis in baseline staging $(17.1 \%$ vs. $11.3 ; \mathrm{P}=0.016)$.

\section{Table 2. Perioperative outcomes}

\begin{tabular}{lllll}
\hline & Right & Left & Sigmoid & $P$ \\
\hline Laparoscopic surgery & $26.4 \%$ & $24.4 \%$ & $28.9 \%$ & 0.61 \\
Conversion in laparoscopy & $10.6 \%$ & $21.4 \%$ & $13.2 \%$ & 0.32 \\
Multivisceral resection & $14.5 \%$ & $18.1 \%$ & $10.6 \%$ & 0.11 \\
Duration of surgery (median, min) & 108 & 139 & 139.5 & 0.006 \\
Duration of admission (median, days) & 5 & 5 & 4 & 0.048 \\
T-stage 4 & $23.5 \%$ & $29.1 \%$ & $19.8 \%$ & 0.12 \\
Lymph-node positive & $38.7 \% \%^{*}$ & $47.2 \%$ & $44.1 \%$ & 0.13 \\
Pathology & $24.3 \% \%^{\star \star \star}$ & $16.8 \%$ & $10.8 \% \%^{* \star \star}$ & $<0.001$ \\
High grade tumor & $28.2 \%$ & $32.5 \%$ & $33.1 \%$ & 0.30 \\
Extramural vascular invasion & $21.0 \%^{*}$ & $23.8 \%$ & $29.0 \%^{*}$ & 0.044 \\
30-day Metastasis & $15.8 \%$ & $16.5 \%$ & $20.2 \%$ & 0.30 \\
Liver & $11.1 \%$ & $11.8 \%$ & $17.1 \%{ }^{*}$ & 0.054 \\
Lung & $2.0 \%$ & $1.6 \%$ & $2.3 \%$ & 0.89 \\
Peritoneal & $3.2 \%$ & $0.8 \%$ & $2.7 \%$ & 0.31 \\
Retroperitoneal/mesenteric & $2.5 \%$ & $2.4 \%$ & $1.1 \%$ & 0.43 \\
Omentum & $2.2 \%$ & $2.4 \%$ & $1.9 \%$ & 0.95 \\
Ovary (female population) & $1.7 \%$ & $1.7 \%$ & $3.4 \%$ & 0.54 \\
Bone & $0.9 \%$ & $0.0 \%$ & $0.8 \%$ & 0.56 \\
\hline
\end{tabular}

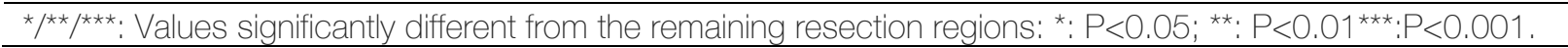

Follow-up and recurrence

When outcomes were compared among all three major resection regions, statistically significant differences were found in rates of lung metastasis during follow-up $(\mathrm{P}<0.001)$, and significant differences in cumulative rates of liver $(\mathrm{P}=0.04)$ and lung $(\mathrm{P}<0.001)$ metastases. Median follow-up duration was similar in right, left and sigmoid tumors at 42,41 and 45 months respectively $(\mathrm{P}=0.33)$, and loss to follow-up rates of $4 \%, 6.1 \%$ and $6.1 \%(\mathrm{P}=0.40)$. Mortality rates $(\mathrm{P}=0.36)$ and duration of survival $(\mathrm{P}=0.35)$ and disease-free survival $(\mathrm{P}=0.82)$ were not substantially different between major resection groups. With respect to specific regions, right-sided tumors had significantly lower rates of local recurrence ( 0.7 vs. $2.3 \%$; $=0.039)$ and lung metastasis $(2.7$ vs. $9.0 \% ; \mathrm{P}<0.001)$ in follow-up, as well as lower cumulative rates of overall metastasis $(24.8$ vs. $31.8 \%$; 
$\mathrm{P}=0.017)$, mostly owing to the significantly higher cumulative rates of liver (15.6 vs. 22.1\%; $\mathrm{P}=0.012)$ and lung metastasis $(4.7$ vs. $11 \% ; \mathrm{P}<0.001)$. For left-sided resections, the overall percentage of metastatic recurrence was highest at $15 \%$ (vs. $9.9 \%$ in other resections; $\mathrm{P}=0.083$ ) likely related to the significantly higher rate of liver metastases during follow-up ( 9.4 vs. 4.8\% $\mathrm{P}=0.029)$. Sigmoid resections had the highest rates of lung metastasis during follow-up (9.9 vs. $3.5 \% ; \mathrm{P}<0.001)$, along with considerably higher overall rates of liver $(22.4$ vs. $16.7 \% ; \mathrm{P}=0.04)$ and lung metastases $(12.2$ vs. $5.4 \%$; $<0.001)$. Incidentally, in stage II tumors, sigmoid resections were shown to have a longer disease-free survival duration (51 vs. 41 weeks; $\mathrm{P}=0.048$ ) and survival duration (61 vs. 49 weeks; $\mathrm{P}=0.021$ ).

\section{Table 3. Long-term outcomes}

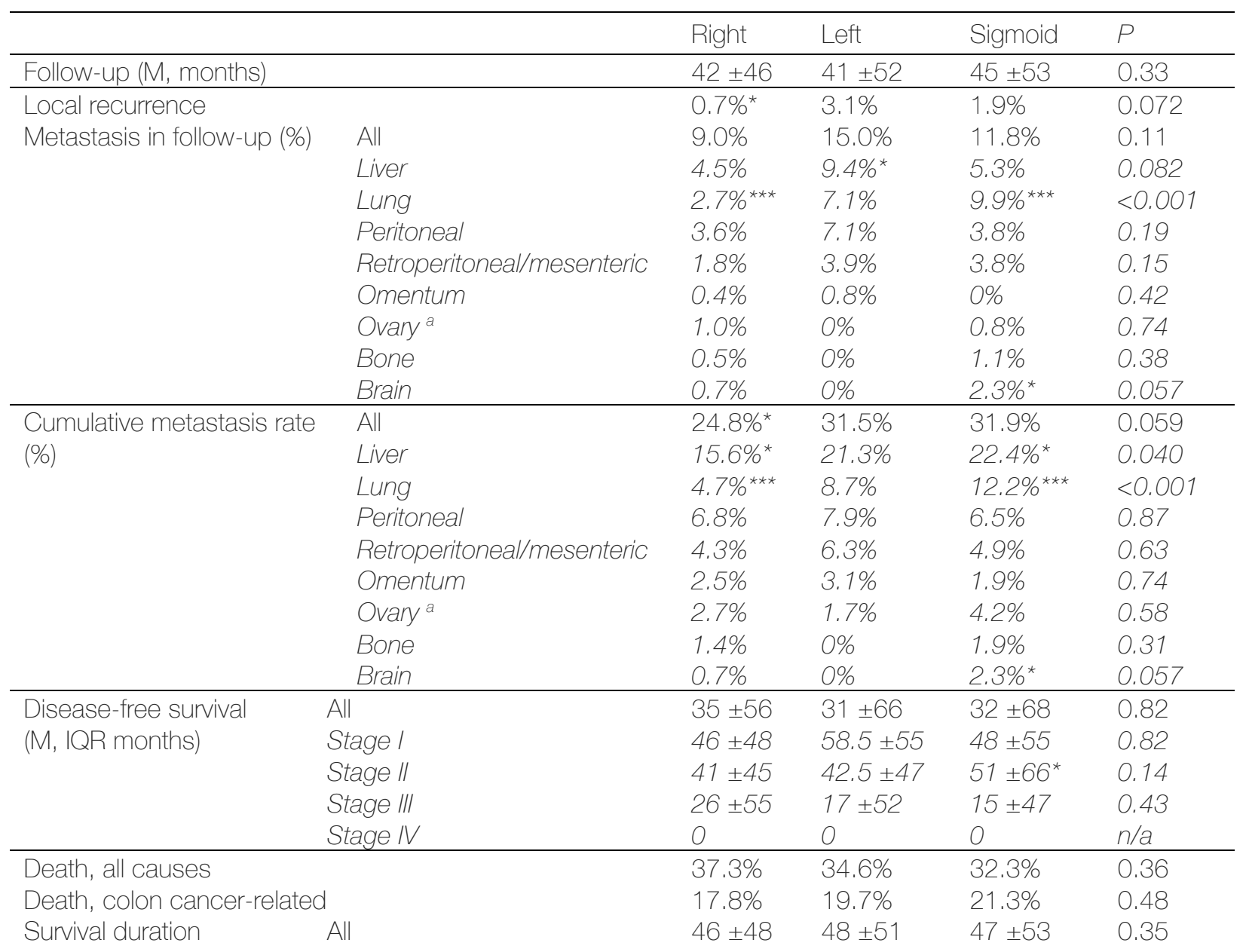




\begin{tabular}{cccccc} 
(M, IQR months) & Stage I & $52 \pm 50$ & $66.5 \pm 45$ & $56 \pm 52$ & 0.88 \\
& Stage II & $49 \pm 41$ & $50 \pm 46$ & $61 \pm 55^{*}$ & 0.056 \\
& Stage III & $38 \pm 46$ & $36 \pm 66$ & $42 \pm 44$ & 0.57 \\
& Stage IV & $12.5 \pm 37$ & $30.5 \pm 29$ & $21 \pm 32$ & 0.61 \\
\hline${ }^{* / * / * * *}$ : Values significantly different from the remaining resection regions: ${ }^{*}: P<0.05 ;{ }^{* *}: P<0.01^{* * *}: P<0.001$
\end{tabular}

Multivariate Cox regression, as shown in Table 4, demonstrates that differences in metastatic outcomes between resection regions was only marginally influenced by baseline AJCC staging, as all differences remained statistically significant in stage-adjusted multivariate models, with the exception of the lower overall metastasis rates in right-sided tumors $(\mathrm{P}=0.011)$ and liver metastasis during follow-up in left-sided tumors $(\mathrm{P}=0.134)$; both outcomes still had an high point estimate multivariate hazard ratios of $\mathrm{mHR}=1.24$ (95\%CI: $0.96-1.60)$ and $\mathrm{mHR}=1.64$ (95\%CI: $0.86-3.15)$, respectively. Right sided tumors still had lower stage-adjusted hazards of pulmonary metastasis in follow-up $\mathrm{mHR}=0.32(95 \% \mathrm{CI}$ : $0.17-0.58 ; \mathrm{P}=0.001)$ and lower overall stage-adjusted liver metastasis hazards $\mathrm{mHR}=0.74(95 \% \mathrm{CI}: 0.55-0.99 ; \mathrm{P}=0.050)$. Sigmoid resections had stage-independent overall hazards of lung $(\mathrm{mHR}=2.26,95 \% \mathrm{CI}$ : 1.41-3.63; $\mathrm{P}=0.001)$ and brain metastases $(\mathrm{mHR}=4.03$, 95\%CI: 1.14-14.3; $\mathrm{P}=0.031)$. In line with univariate models, other sites of metastasis, including the (retro)peritoneum, omentum, ovary and bone, did not yield significant differences in multivariate analysis.

\section{Table 4. Univariate and stage-adjusted analysis}

\begin{tabular}{|c|c|c|c|c|c|c|c|c|c|}
\hline & \multicolumn{3}{|l|}{ Right } & \multicolumn{3}{|l|}{ Left } & \multicolumn{3}{|l|}{ Sigmoid } \\
\hline & $\begin{array}{l}\text { Univariate } \\
\text { HR }(95 \% \mathrm{Cl})\end{array}$ & $\begin{array}{l}\text { Multivariate } \\
\text { HR }(95 \% \mathrm{Cl})\end{array}$ & $\mathrm{P}$ & $\begin{array}{l}\text { Univariate } \\
\text { HR }(95 \% \mathrm{Cl})\end{array}$ & $\begin{array}{l}\text { Multivariate } \\
\text { HR }(95 \% \mathrm{Cl})\end{array}$ & $\mathrm{P}$ & $\begin{array}{l}\text { Univariate } \\
\text { HR }(95 \% \mathrm{Cl})\end{array}$ & $\begin{array}{l}\text { Multivariate } \\
\text { HR }(95 \% \mathrm{Cl})\end{array}$ & $\mathrm{P}$ \\
\hline Local recurrence & $0.33(0.10-1.07)$ & $0.35(0.11-1.13)$ & 0.079 & $2.75(0.85-8.94)$ & $2.61(0.80-8.5)$ & 0.11 & $1.57(0.51-4.79)$ & $1.50(0.49-4.59)$ & 0.48 \\
\hline Metastatic recurrence & $0.66(0.45-0.98)$ & $0.74(0.50-1.09)$ & 0.126 & $1.53(0.93-2.52)$ & $1.29(0.78-2.13)$ & 0.32 & $1.25(0.82-1.91)$ & $1.21(0.79-1.85)$ & 0.37 \\
\hline Liver & $0.64(0.37-1.11)$ & $0.73(0.42-1.26)$ & 0.26 & $2.00(1.05-3.82)$ & $1.64(0.86-3.15)$ & 0.134 & $1.04(0.56-1.92)$ & $1.01(0.55-1.87)$ & 0.98 \\
\hline Lung & $0.29(0.16-0.53)$ & $0.32(0.17-0.58)$ & $<0.001$ & $1.45(0.69-3.06)$ & $1.25(0.61-2.58)$ & 0.54 & $2.91(1.67-5.07)$ & $2.85(1.64-496)$ & $<0.001$ \\
\hline Overall Metastasis & $0.76(0.60-0.74)$ & $0.82(0.65-1.05)$ & 0.011 & $1.17(0.83-1.64)$ & $1.04(0.74-1.45)$ & 0.86 & $1.26(0.97-1.63)$ & $1.24(0.96-1.60)$ & 0.11 \\
\hline Liver & $0.70(0.52-0.94)$ & $0.74(0.55-0.99)$ & 0.050 & $1.20(0.79-1.81)$ & $1.08(0.72-1.63)$ & 0.72 & $1.37(1.00-1.87)$ & $1.35(0.99-1.85)$ & 0.061 \\
\hline Lung & $0.42(0.26-0.68)$ & $0.45(0.27-0.73)$ & 0.001 & $1.23(0.64-2.34)$ & $1.09(0.57-2.09)$ & 0.78 & $2.30(1.44-3.70)$ & $2.26(1.41-3.63)$ & 0.001 \\
\hline Brain & $0.45(0.13-1.59)$ & $0.49(0.14-1.74)$ & 0.27 & No cases & - & - & $4.07(1.15-14.4)$ & $4.03(1.14-14.3)$ & 0.031 \\
\hline
\end{tabular}

\section{Discussion}


Malignancies of the colon are usually clustered as a single entity when patterns and incidence rates of metastasis are discussed. We hypothesized that the clinical reality is different, and that significant differences exist in metastatic patterns depending on the location of the primary tumor. We found that significant differences exist within the three primary resection regions in hematologic metastasis and with a smaller and non-significant trend in lymph node metastasis.

Specifically, right-sided tumors had more clement metastatic outcomes, including lower rates of lymph node, overall distant metastasis and lung metastasis. Left-sided tumors had significantly higher liver metastasis rates during follow up. Sigmoid tumors had considerably worse characteristics, including higher total rates of lung and brain metastasis and higher liver metastasis rates at baseline. These differences were found to be independent of baseline AJCC staging.

Earlier evidence confirms some of our findings: a 1980's long-term follow-up study at the Peter Bent Brigham hospital of 281 curative resections gave indications that sigmoid resections were at the highest odds of recurrence. ${ }^{5}$ The vast majority of the body of evidence is based on the leftright dichotomy in outcomes that was proposed over two decades ago. ${ }^{6}$ Most of this research was aimed at site-specific (disease-free) survival, baseline characteristics and staging, and only rarely focusing specifically on patterns of metastasis: ${ }^{7}$ using this left-right dichotomy, a German multicenter study demonstrated higher rates of pulmonary and liver metastasis in left-sided tumors, ${ }^{8}$ on the other hand however, a Japanese study covering a single-center cohort of 820 patients could not identify significant differences in sites of metastasis. ${ }^{?}$

There are several possible explanations for the differences in metastatic patterns identified here. A first candidate is the sessile serrated pathway, which in the colon is mostly prominent in right-sided tumors and may be responsible for up to $16 \%$ of all proximal colonic tumors. ${ }^{10}$ Rightsided tumors have a clearly lower rate of metastasis, and with about $15 \%$ of these tumors occurring through the sessile serrated pathway, this could explain the more indolent course of right-sided 
tumors in general, although evidence proving this effect is still too sparse to allow the assumption of a causal relationship. However, although we do not have specific pathologic data on previous polyps resected from patients in our cohort, we did note a markedly higher rate of preexisting polyposis in those patients with right-sided tumors, which supports this hypothesis. Secondly, other inherent differences in tumor genetics, mutation profiles and subsequent biology and histologic subtype ${ }^{11}$ may cause differences both in local behavior and later seed-and-soil characteristics. ${ }^{12}$ Lastly and most intuitively, the analyzed colonic segments have anatomically distinct and discrete lymphatic and vascular drainage areas, which may well lead to different seeding patterns, as parts of the colonic drainage maybe more or less likely to reach the hepatic circulation.

This research clearly has its limitations: although the overall population size was large enough to identify overall population-level patterns in metastatic disease. It was too small to identify stagespecific differences between resection regions. Similarly, due to the limited number of patients tested for microsatellite instability or mutations (BRAF, KRAS, etc.), these investigations into genetic variation did not yield any meaningful findings in preliminary data exploration and were therefore not a significant contribution to the data described in this paper. Further research on the topic may well deliver important insights on the underlying effects of these mutations on the described differences in metastasis patterns.

In conclusion, the applicability of the metastatic differences demonstrated here lies in the difference in the odds of having specific metastasis or pathological characteristics. These differ considerably depending on the region of the primary resection and, ideally, if these findings are confirmed in larger population studies, these differences have implications on the surveillance and adjuvant treatment of colonic malignancies, which could include a lower threshold for adjuvant therapy in left-sided disease and varied rates of surveillance computed tomography frequencies. 


\section{References}

1. Kindler HL, Shulman KL. Metastatic colorectal cancer. Curr Treat Options in Oncol. 2001;2(6):459-471.

2. Weiss L, Grundmann E, Torhorst J, et al. Haematogenous metastastic patterns in colonic carcinoma: an analysis of 1541 necropsies. J Pathol. 1986;150(3):195-203.

3. Siegel R, Desantis C, Jemal A. Colorectal cancer statistics, 2014. CA Cancer J Clin. 2014;64(2):104-117.

4. $\mathrm{Li} \mathrm{M}, \mathrm{Li} \mathrm{JY}$, Zhao $\mathrm{AL}, \mathrm{Gu}$ J. Colorectal cancer or colon and rectal cancer? Clinicopathological comparison between colonic and rectal carcinomas. Oncology. 2007;73(1-2):5257.

5. Olson RM, Perencevich NP, Malcolm AW, Chaffey JT, Wilson RE. Patterns of recurrence following curative resection of adenocarcinoma of the colon and rectum. Cancer. 1980;45(12):2969-2974.

6. Iacopetta B. Are there two sides to colorectal cancer? Int J Cancer. 2002;101(5):403-408.

7. Lee GH, Malietzis G, Askari A, Bernardo D, Al-Hassi HO, Clark SK. Is right-sided colon cancer different to left-sided colorectal cancer? - a systematic review. Eur J Surg Oncol. 2015;41(3):300-308.

8. Benedix F, Kube R, Meyer F, et al. Comparison of 17,641 patients with right- and left-sided colon cancer: differences in epidemiology, perioperative course, histology, and survival. Dis Colon Rectum. 2010;53(1):57-64.

9. Moritani K, Hasegawa H, Okabayashi K, Ishii Y, Endo T, Kitagawa Y. Difference in the recurrence rate between right- and left-sided colon cancer: a 17-year experience at a single institution. Surg Today. 2014;44(9):1685-1691.

10.Tuppurainen K, Mäkinen JM, Junttila O, et al. Morphology and microsatellite instability in sporadic serrated and non-serrated colorectal cancer. J Pathol. 2005;207(3):285-294.

11.Hugen N, van de Velde CJH, de Wilt JHW, Nagtegaal ID. Metastatic pattern in colorectal cancer is strongly influenced by histological subtype. Ann Oncol. 2014;25(3):651-657.

12.Sun C, Zargham R, Shao Q, et al. Association of CD98, integrin $\beta 1$, integrin $\beta 3$ and Fak with the progression and liver metastases of colorectal cancer. Pathol Res Pract. 2014;210(10):668-674. 
